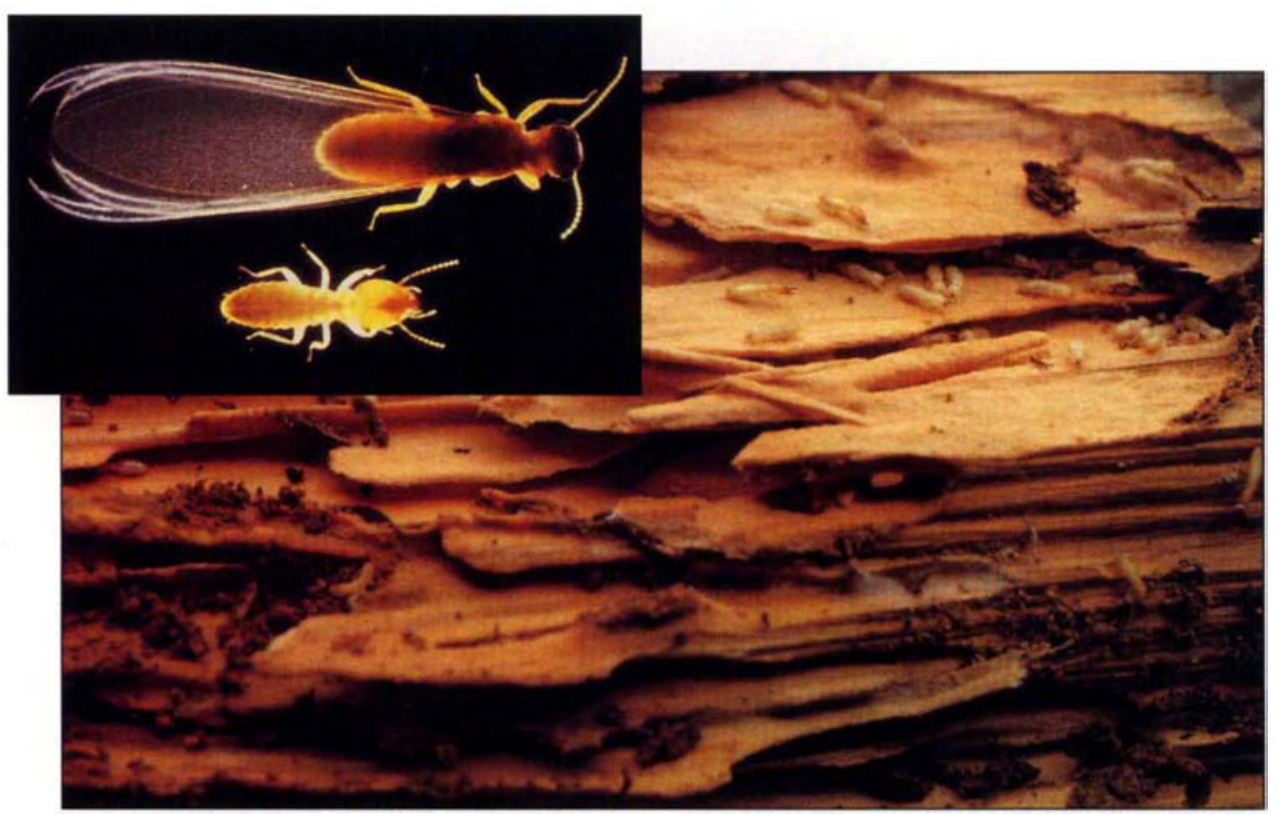

Coptotermes formosanus Shlrakl - winged reproductive, top, and worker, bottom of inset. Large populations of the nonnative termite can cause significant structural damage within 6 months and can destroy an unprotected home within 2 years.

\section{Formosan subterranean termite established in California}

\author{
Karl Haagsma $\square$ Michael K. Rust a Donald A. Reierson \\ Thomas H. Atkinson a David Kellum
}

months and may almost destroy an unprotected home within 2 years. Methods to protect homes from Coptotermes damage include use of wire mesh or sand barriers, pretreatment with a chemical termiticide and remedial soil treatment with termiticide. In instances where the termite colony has no contact with the ground, fumigation has been successfully used to eradicate colonies. However, there is no technique yet available for areawide eradication of $C$. formosanus.

C. formosanus biology is typical of most subterranean termites. They are social insects that live in colonies and divide colony labor among specialized castes. The queen and king are responsible for reproduction, the workers gather food and maintain the nest and soldiers, equipped with ferocious mandibles and defensive chemicals, protect the colony from predators. New colonies begin from a pair of mated individuals. Some workers in the colony differentiate to a reproductive winged form and participate in swarms, where male and female alates leave the colony, take a short flight and mate after they shed their wings. Mated pairs attempt to initiate new colonies.

Termites can be divided into two groups on the basis of nesting site. Subterranean termites are ground nesting and tunnel through the soil to find food sources. Drywood termites live within their food source, requiring no contact with the ground. $C$.

formosanus is an example of a subterranean termite, but it may construct isolated aerial colonies that have no contact with the ground, provided sufficient water is available. In fact, colonies of $\mathrm{C}$. formosanus have been

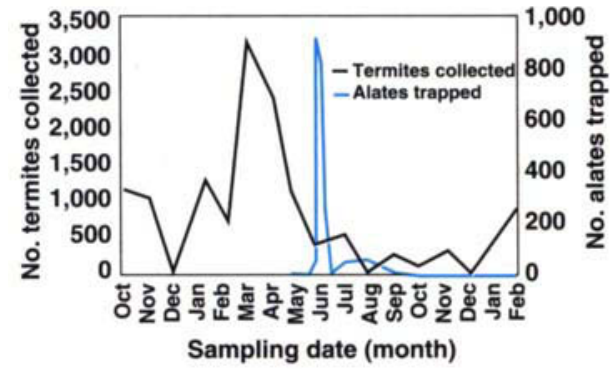

Fig. 1. Number of workers and soldiers collected from ground traps and number of alates caught on sticky traps in La Mesa from October 1992 to February 1994. 
found on the roofs of high-rise condominiums in south Florida and Hawaii.

Because $C$. formosanus thrives in humid tropical habitats, it was thought unlikely that this species could be successfully established in California. Tropical insects usually desiccate in dry localities like California unless they find suitable moist microhabitats. However, in February 1992 a population of $C$. formosanus was discovered in La Mesa, a residential area approximately 10 miles (16 kilometers) inland from San Diego. A local pest control operator who had been unable to eliminate a chronic termite problem provided the first specimens. Our tentative identification of $C$. formosanus was confirmed by Dr. Rudi Scheffrahn at the University of Florida. Based on the size of soldier head capsules, the colony was estimated to be at least 10 years old. The average soldier head capsule size increases with colony age (Scheffrahn, personal communication). The population was probably originally introduced at a single property more than 10 years ago in wooden belongings or in potted plants transported from Hawaii.

Because of the destructive potential of this termite and the environmental differences between California and other geographic locations where this

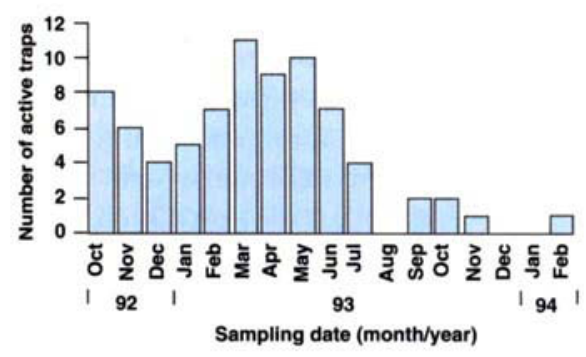

Fig. 2. Number of active Coptotermes foraging sites in La Mesa from October 1992 to February 1994.

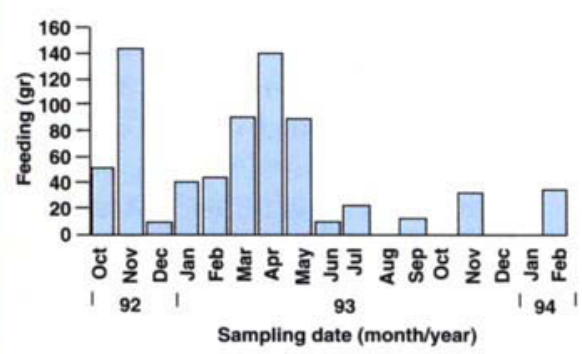

Fig. 3. Total amount of wood consumed in traps at La Mesa from October 1992 to February 1994.

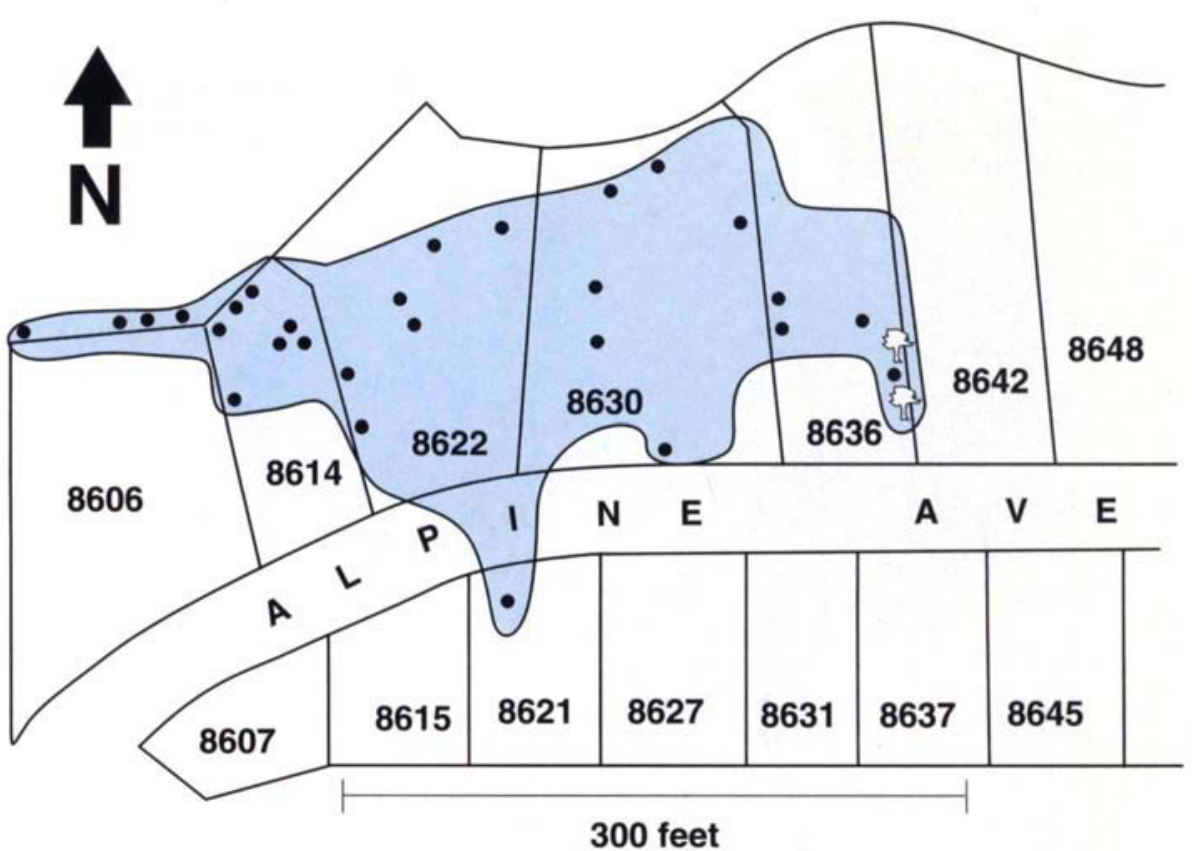

Fig. 4. Distribution of termite captures in permanent traps around Alpine Avenue in La Mesa. Black dots indicate permanent traps where termites were found.

termite is commonly found, a study was made to assess the extent of the infestation and, in conjunction with county agencies, to develop possible strategies to control or eradicate the Formosan termite in Southern California.

\section{Study techniques}

Ground monitoring. In May 1992 a wooden stake monitoring system was installed. Approximately 1,000 Douglas fir construction stakes ( 3.6 by 1.2 by 43 centimeters each) were driven into the ground at 5 -foot intervals in continuous lines around structures, adjacent to walkways and driveways, on the perimeter of lawns and in flower beds on 16 contiguous properties on Alpine and Sunrise Avenues in La Mesa surrounding the supposed center of the infestation. Beginning in September 1992 and continuing monthly, each monitor stake was inspected for termites and damage. In the event of termite activity at a stake, a permanent monitoring trap was installed to collect termites to eventually provide a way to estimate the size and range of the infestation. Each trap consisted of a 14.6-centimeter long, 9.7centimeter diameter PVC pipe buried vertically in the ground by the infested stake. A preweighed wooden wafer (measuring 7.5 by 9.0 by 0.6 centimeters) made of several thin sections of Douglas fir was placed inside the trap. The PVC pipe was then sealed with a plastic cap. The traps were inspected monthly when the monitor stakes were examined. If termites were active at a particular trap, the wafer was removed and returned to the laboratory for recording of the number of workers and soldiers. The amount of feeding was calculated from the difference between the initial weight of the wafer and its weight after being attacked by termites.

A triple mark-release-recapture technique was used to determine the population size and extent of foraging area of $C$. formosanus in La Mesa. Termites collected from the most active ground trap in April 1993 were returned to the laboratory and allowed to feed on filter paper stained with Nile Blue, a histological dye. This dye stains the termites noticeably blue, has little effect on them and is retained by the termites for several weeks. In May the dyed termites were then released into the trap from which they were collected. Later that month termites from all the active traps were collected, and the number of blue termites was determined. The termites from all traps where dyed termites 


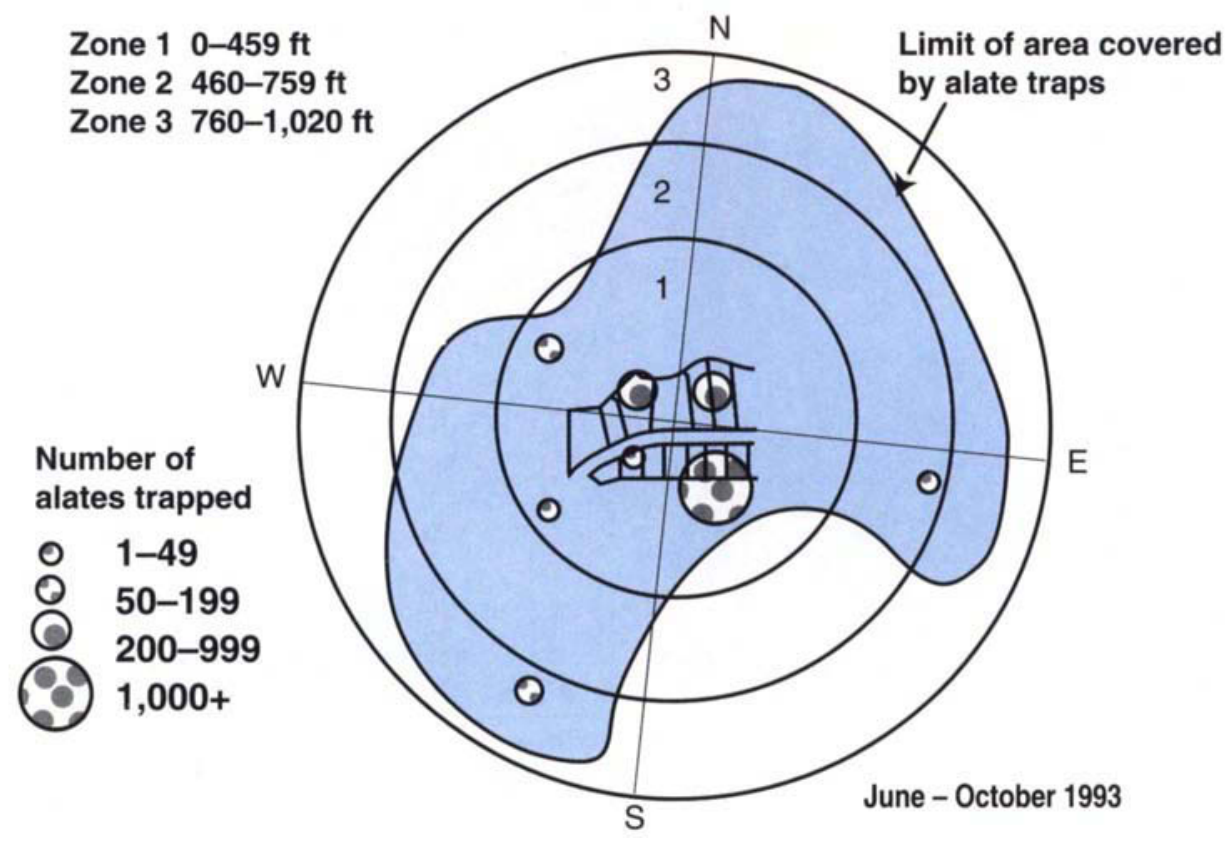

Fig. 5. Distribution of alate catches in sticky traps from June to October 1993, showing the distance and direction they flew. Gray shading indicates the area covered by the alate traps.

were found were returned to the laboratory and fed filter paper dyed with Sudan Red (another histological dye). The red termites were then released into a PVC trap. Later that month termites from all the active traps were again collected, and the number of dyed termites (blue and red) was counted. The proportion of dyed to nondyed termites on both sampling days was used to estimate colony size. The distance between traps from which dyed termites were recovered provided an estimate of the area over which a colony forages.

Alate traps. In 1992 swarms of winged reproductive (alate) $C$. formosanus in La Mesa were monitored with sticky traps hung near lights on 18 properties near the home at which the termites were first discovered. Similar monitoring was done in 1993, but the trap area was enlarged to include 42 properties in the surrounding neighborhood. The traps were inspected biweekly from May to September, and the number of $C$. formosanus alates trapped was recorded.

Baiting. A novel control strategy for ground-nesting colonies of Coptotermes incorporates a slow-acting toxic bait. Worker termites feed on the bait and pass the bait throughout the colony, potentially killing the queen. As workers feed on the bait, the amount of toxicant builds up in the colony, and the reproductives die. Baiting is especially appropriate for use with Coptotermes because one queen is solely responsible for reproduction and new queens are not produced if the original queen dies. Since Coptotermes colonies do not "bud," or form satellite colonies in which secondary reproductives replace the queen and start new colonies, the entire colony dies once the original queen is killed. The active ingredient in the bait used in La Mesa is a chitin synthesis inhibitor, hexaflumuron, which controls the production of chitin during the molting process.

The toxic bait was presented to the Coptotermes in La Mesa in July 1993. Tubes of bait were placed in three active ground traps and in PVC pipe traps installed in several infested trees. Bait tubes were checked at trap collections to determine if the bait was fed upon or tunneled through.

\section{Results and discussion} collected, $C$. formosanus foraging activity in La Mesa was greatest in March
Based on the number of termites and April (fig. 1). As expected, the number of ground traps with active foraging termites corresponded directly with the total number of foragers collected (fig. 2), and feeding activity of the termites demonstrated a slightly significant correlation to the number of termites collected per month $\left(R^{2}=0.54\right)$. Figure 3 shows that feeding was greatest in November 1992 and from March to May 1993. It appears that the best conditions for $C$. formosanus foraging in La Mesa occur in the spring season, prior to the hot, dry conditions of summer. Temperature highs of $90^{\circ} \mathrm{F}$ and relative humidity as low as $10 \%$ at La Mesa may adversely affect $C$. formosanus. Smith and Rust (1993) have found that survivorship of the western subterranean termite, Reticulitermes hesperus, was related to temperature and relative humidity, with high temperatures and low humidity resulting in rapid kill.

Activity and feeding at a given trap were extremely variable. A trap with hundreds of termites in 1 month often had only a few termites just 1 month later. Apparently, disturbance of the traps can dramatically affect the termites' foraging behavior.

The C. formosanus population in $\mathrm{La}$ Mesa was estimated to be 100,852 $( \pm 21,667)$ individuals. However, homeowners had observed several alate flights of what they estimated at several hundred thousand individuals. In fact, we estimated one swarm in 1993 to involve 2.6 million alates. The major problem associated with population estimation in this situation was the relatively few termites that were captured, dyed and released. Low numbers could cause underestimation of population size. Furthermore, technique success is based on the assumption that there is sustained foraging activity at the monitoring traps. This assumption is not met in the La Mesa termite population.

The monitoring studies indicated that the C. formosanus population in $\mathrm{La}$ Mesa was limited to seven contiguous properties (fig. 4). Recent discoveries of C. formosanus slightly beyond the original proven foraging area south of Alpine Avenue suggest the colony 
may be expanding its foraging. A trap at 8621 Alpine had been initially been active for western subterranean termites, Reticulitermes hesperus, but $C$. formosanus displaced them in July 1993. The area to the north of $8606 \mathrm{Al}-$ pine is a vacant unirrigated field with a decomposed granite soil type.

Formosan termites were discovered along a property adjacent to this field in March 1994.

Alate traps. A majority of the alates were trapped within 500 feet of 8614 Alpine, where large swarms were observed by the homeowner (fig. 5), but a few were trapped as far as 900 feet away from the source of the swarm. A prevailing westerly wind was probably responsible for the large numbers of alates that were trapped in the southeast direction. The swarmers may fly even farther, because some of them were trapped near the perimeter of the trapping area to the southeast and northwest. The greatest number of alates was trapped on June 11 and 17, 1993, with total trap counts of 926 and 828 termites, respectively. Although probably coincidental, the swarm in La Mesa occurred on the same day there was a major Coptotermes swarm at the location in Hawaii from which these termites may have originated. Swarming occurred following times of peak termite feeding activity in March and April (fig. 1). This may represent increased foraging activities and increased energy input into development and provisioning of the reproductives of the colony in preparation for the reproductive flight.

Implied by the size of the flight and the distances covered is the possibility that new colonies have been founded. The question remains whether environmental factors and urban microhabitats favor the success of a naturally forming colony as opposed to an established colony being introduced to an area. To date, there have been no reports from homeowners or pest control operators of Coptotermes being sighted outside the original La Mesa site. Given that the original colony at La Mesa probably went undetected for more than 10 years, it may be several more years before we will know if swarmers have successfully estab- lished new colonies beyond the area of original introduction.

Control. To date, termites have visibly tunneled in one ground trap and several tree trap baits. One bait in the tree was fed upon or removed by the termites so that there was a noticeable decrease in material. The baits dyed with Nile Blue were also tested to determine the amount of bait being consumed and whether bait was being spread throughout the colony. No blue termites have been recovered yet, probably because the amount of feeding by an individual termite is so small the dye mark is not noticeable. However, a lot of feeding may not be necessary to suppress a colony. In preliminary baiting trials in Florida, an estimated population of 1 million Formosan termites was eliminated after feeding on 233 milligrams of active bait ingredient, and a population of Eastern subterranean termites

(Reticulitermes flavipes) estimated at 500,000 individuals appeared to be eliminated after consuming as little as 4 milligrams of active ingredient.

Evaluation of the success of a baiting strategy depends upon some kind of population estimation before and after baiting. Since a mark-releaserecapture population estimation does not work well at the La Mesa site because of low trap catch, we must rely on the continued monitoring of termite numbers, wood consumed and alate swarms. On an encouraging note, the amount of feeding, the number of termites collected at traps and the number of active traps during September and October 1993 were substantially less than for the same months in 1992. This could be an indication that the bait is working.

Another control strategy utilized to supplement baiting is sanitation. When visual inspection of the properties was conducted, several properties had piles of firewood or discarded lumber that were heavily infested with Coptotermes. Cleanup of the wood limits the amount of acceptable food
PVC pipe traps filled with a slow-acting toxic bait were installed in Formosan subterranean termite-infested pepper trees. Ideally as worker termites feed on the bait, the toxicant builds up in the colony and kills the reproductives.

sources available to the termites. Use of this strategy in addition to baiting may help limit the growth and expansion of the colony.

K. Haagsma is Graduate Student, M.K. Rust is Professor and Chair, D.A.

Reierson is Staff Research Associate and T.H. Atkinson is Assistant Entomologist and Assistant Cooperative Extension Specialist, all in the Department of Entomology, UC Riverside. D. Kellum is Senior Economic Entomologist, Department of Agriculture, San Diego County.

The authors wish to thank J. Lewis, $B$. Phillips, J. Virzi, D. Hawks, E. Paine, B. Cabrera, J. Murray-Roseberry, T. Breuninger, M. Bartko, and S. Cote for their assistance in monitoring activities and Dr. R. Scheffrahn and Dr. N.-Y. Su of the University of Florida, Gainesville, for termite identification. Technical information, bait formulations and support for this project were supplied by DowElanco. 